\title{
Modelling Teachers' Behaviour in ICT Usage
}

\author{
Suhamira Nordin, Kamariah Yunus
}

To Link this Article: http://dx.doi.org/10.6007/JJARBSS/v11-i2/9194

DOI:10.6007/IJARBSS/v11-i2/9194

Received: 13 December 2020, Revised: 17 January 2021, Accepted: 27 January 2021

Published Online: 19 February 2021

In-Text Citation: (Nordin \& Yunus, 2021)

To Cite this Article: Nordin, S., \& Yunus, K. (2021). Modelling Teachers' Behaviour in ICT Usage. International Journal of Academic Research in Business and Social Sciences, 11(2), 984-994.

Copyright: (c) 2021 The Author(s)

Published by Human Resource Management Academic Research Society (www.hrmars.com)

This article is published under the Creative Commons Attribution (CC BY 4.0) license. Anyone may reproduce, distribute, translate and create derivative works of this article (for both commercial and non-commercial purposes), subject to full attribution to the original publication and authors. The full terms of this license may be seen

at: http://creativecommons.org/licences/by/4.0/legalcode

Vol. 11, No. 2, 2021, Pg. 984 - 994

Full Terms \& Conditions of access and use can be found at http://hrmars.com/index.php/pages/detail/publication-ethics 


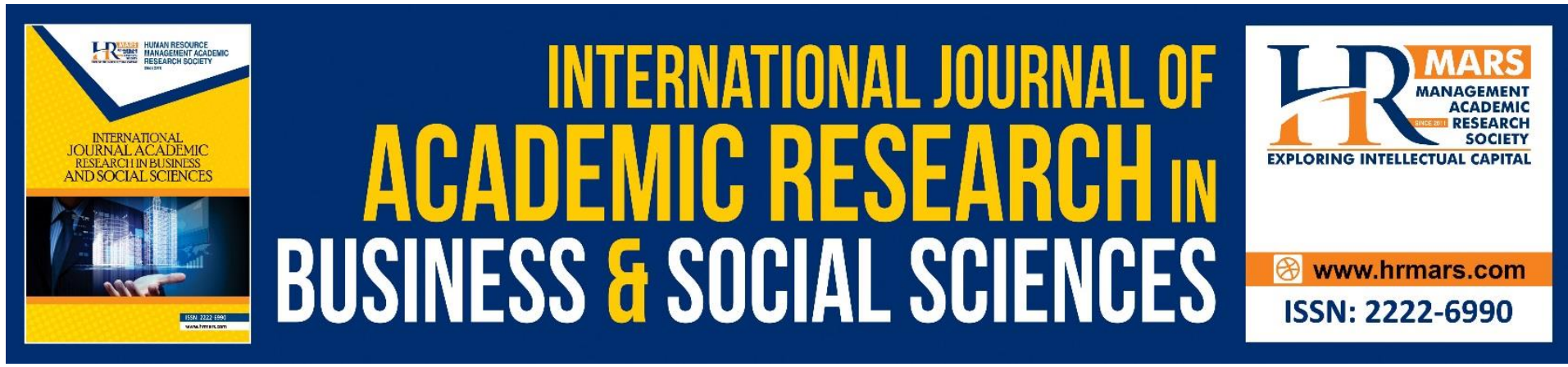

\title{
Modelling Teachers' Behaviour in ICT Usage
}

\author{
Suhamira Nordin, Kamariah Yunus \\ Faculty of Languages and Communication, University of Sultan Zainal Abidin, Gong Badak \\ Campus, 21300 Kuala Terengganu, Malaysia
}

\begin{abstract}
In response to the global pandemic effect on the education field, the growth of the Internet of Things (IoT), Artificial Intelligence, Information and Communication Technology (ICT), are becoming more exposed and rapidly utilized. In the English as a Second Language Teaching (ELT) context, teachers are expected to swiftly evolve with technology. However, it is more important to investigate the teachers' technology learning process and their emerging ability to adapt pedagogy to a virtual classroom and provide effective lessons. Although many studies have highlighted the perceptions, challenges, and barriers in integrating technology in the lesson, it is crucial to understand the important role of a teacher's development of different human capabilities to react to technology integration in teaching and learning. The aim of this paper is to investigate the influence of the knowledge and pedagogical beliefs of ESL teachers on the use of ICT in teaching and learning environments. The influence elements delineate the reciprocal causation in behaviour, personal characteristics, and environment of three variables with a bidirectional interaction. This structure will bring many contributions to how ESL teachers perceive their own self-system and exploit technological resources for an adaptive and interactive teaching strategy with a multimodal outcome. The paper concludes with practical implications for the educators, stakeholders, and professional development planners for further actions.
\end{abstract}

Keywords: ICT Usage, English Language Teaching, Technology Integration, Reciprocal Causation, Teachers' Development

\section{Introduction}

The emergence of the global coronavirus pandemic outbreak made a savior of technology for sustaining learning in the education sector. The closure of schools, which was done in order to avoid mass gatherings and to ensure social distancing, has resulted in $91.3 \%$ of (approximately 1.5 billion) registered students throughout the world not being able to return to school because of Covid19(UNESCO, 2020). It also has been experienced by 2.5 million Malaysian students who are at high risk of falling behind (MoE, 2020). The core business of Malaysian teachers and educators has been challenged with an unknown outcome. Despite this undetermined future of education, there is a great drive for the rapid exposure of using technology in education. As teachers and educators shift to emergency remote teaching, technological skills are being promoted in fast-track courses just in time to sustain teaching 
and learning. Though the teachers' skills are geared up, how much can effective lessons suit the primary schoolers?

In the context of language teaching, especially learning English as a second language, the use of technology integration, for example, Computer Assisted Language Learning (CALL), has been discussed since 1980 by the key figures in the field, Warschauer and Healey (1998). Each conceives of three stages in the development and use of technology in teaching. The first stage is Behaviouristics, secondly Communicative, and thirdly Integrative. Behaviouristics according to Warschaeur (1998), starts with repetitive language drills and the computer takes on the role of an automated tutor with no judgment and fatigue, which allows students to learn at their own pace. From the late 1940s to 1980s, the transition to the communicative stage focused on computer-based activities that emphasized using the forms rather than on the forms itself. In other words, Grammar was taught implicitly in exchange to explicitly generate original utterances over manipulated prefabricated language which, in turn, encouraged the student to use the target language exclusively. The third stage was the integrative phase, which was a shift from the cognitive view of communicative teaching to a more social or socio cognitive view. It is placing a greater emphasis on the language being used in an authentic social context. The learning is characterized by task-based, projectbased, and content-based themes which are integrated into learning in a real environment along with various language skills integration.

The impact of Covid-19 can be inferred by significant increase in uploaded YouTube teaching videos by educators including Malaysian instructors (Bergen, 2020). The content of the videos centers mostly on grammar via YouTube live where students and teachers can interact in real time. Furthermore, to organize the virtual class at home, teachers prefer the platform called e- learning for conducting their lesson. E-learning is not new (Soon, 2020), as Malaysia has been one of the pioneering countries to launch technology integration into education since 1999, and is continuing to narrow the digital divide (Ministry of Education Malaysia (MoE), 2018). Frog Virtual Learning environment (VLE) was introduced a few years ago and recently shifted to Google Classroom to improve students' access to learning materials. Furthermore, WhatsApp and Telegram have been also in high demand during movement control order (MCO) as their application is widely used in communication (97.9\%) according to the Department of Statistics Malaysia for mobile users (2019).

Moreover, the Ministry of Education Malaysia (2020) initiated the Digital Educational Learning Initiative Malaysia (Delima) supported by the big three tech companies, namely, Google, Microsoft, and Apple to aid the students while allowing the teachers to choose the learning context mode they are comfortable using. The Frog VLE platform promoted integrative learning before the pandemic and is currently one of the alternative platforms to aiding teachers and students' homeschooling in Malaysia. Nevertheless, students with limited internet access and devices are catered to by MOE launching an Educational TV Program (MoE, 2020b). To this end, students with no network access are limited to the school's administration decision regarding teaching methods and learning processes during $\mathrm{MCO}$ periods (MoE, 2020b). Therefore, Malaysian ESL teachers have many options for continued teaching and learning with technology as the main medium of communication and instruction.

The concept of teaching is illustrated in a set of events which are designed to support the internal process of learning (Sequeira, 2012). In addition, learning and motivation are internal to learners and it is seen with the behavioural or performance outcomes. While the usage of ICT in emergency remote teaching is at an experimental stage for the new and basic users, 
learners' consequences are in high concern. The learners' characteristics need to be customized within the constraints of available tools and resources at home. In addition, primary schooling learners who are familiar with online learning became awkward when changing from a face to face to a reduced interaction medium (Tamin \& Mohamad, 2020). Meanwhile, ESL primary school teachers also face working from home with a lack of technological knowledge and skills. Most of them are merely basic users of technology. Although some teachers agree with using technology indirectly as teaching tools, directly involving students with technology is eschewed in this context (Ghavifekr et al., 2014).

The effect of Covid19 on teaching and learning has caused an abrupt shift in the teaching to a technological medium. Looking back to the history of teachers' integration of ICT in lessons, Melor (2007) found that $98 \%$ of ESL teachers showed minimal use of ICT, while in Hoque, Ahmad Zabidi Abdul Razak, and Zohora (2012) found that $84 \%$ of teachers were not aware of national ICT policy. Auditor General's Survey (2013) states that teacher's use ICT facilities less than $5 \%$ of teachers' time. Cheok, Wong, Ayub, and Mahmud (2020) also reports that schools show low use of ICT. Despite the low usage, however, almost all teachers have basic computer skills. The blessing in disguise for utilizing the technology during the public health crisis is that it brings teachers to use the technology trial and error. Consequently, the teacher's use of the technology can be observed, especially for learning to create comprehensive and customized student English lessons.

\section{Teachers' Behaviour}

Teacher behaviour is an action based on an observable result from the performance of teachers and students that differentiates between the activities of institutions (Shah, 2009). The positive or negative, and the effective or ineffective may be described by behaviour. The term behaviour is to act or present oneself in response to external stimuli, clarified by UNESCO (1986). Teachers also need to be thoughtful and concerned about the impact of technology in the context of living with information at hand for students. In line with the pedagogical context, indicating the requirements of empowering technological knowledge reflects the teachers' behavioural development. Human behavioural development in adapting to technology integration in the context of language learning is explained by the behavioural change model. This reasoning is based on the supposition that better-informed people have increased awareness and consequently, behave responsibly (Akintunde, 2017). Other models similarly highlight the link between knowledge, attitudes, and behaviour. Thus, the behavioural change model explains a linear model of behavioural change that develops when knowledge increment attends with improved attitude and awareness of the teaching and learning environment. Nevertheless, the legitimacy of this simplistic linear model is inadequate for studying multiple variables with multiple dimensions, which is needed for investigating the teachers' behavioural influences in ICT usage for English language lessons. In the context of the present study, the multiple dimensions that influence the teachers' behaviour are delineated by the three set of factors in individuals, schools, and external environment (Webster et al., 2012). There is a line of possible relationships that can be deciphered through this model as reality is more complex than a linear trend. This calls for a more advanced model which can incorporate this complexity in order to engender a succinct explanation about the interacting variables determining teacher's behaviour in ICT use for ELT. While knowledge is a fundamental component of the behaviour change model, Shulman (1987) introduced the concept of Pedagogical Content Knowledge (PCK) to describe the knowledge used by teachers in order to modify or remodel subject matter for learning 
purposes, taking into account learning hurdles. Though PCK has been criticized for being a narrow conceptualization, scholars in different domains have developed specific models of PCK with various adaptations, especially in Mathematics and Science. Meanwhile, in the language and physical education domains, scholars are starting to develop ideas for PCK applications (Berry, Depaepe, \& van Driel, 2016).

The present research employs Mishra and Kohler's (2006) Technological Pedagogical Content Knowledge (TPACK) as a determiner in teacher's behaviour. The wealth of research involving technology use in teaching and learning has mainly focused on the pedagogical issues relating to enhancing student learning and teaching practices (Van Olphen, 2008a). Koehler, Mishra, Kereluik, Shin, and Graham (2014) researched on the instructional use of technology but also exposed teachers lacking knowledge on how to successfully integrate technology into their teaching. Their uses of it are limited in depth and scope. The TPACK framework will be used to determine how English as Second Language (ESL) teachers can more effectively utilize technology to promote language acquisition.

Nevertheless, a good knowledge of technology does not necessarily mean that the integration of ICT will become a seamless part of ELT. On the other hand, a lack of tech knowledge does not necessarily indicate poor teaching practice (Ertmer et al. 2012;Eickelmann \& Vennemann, 2017; Li, 2014; Rahman et al., 2018). Beside technology knowledge, personal (e.g., attitudes, awareness, and beliefs) and environmental factors are crucial elements for determining the teacher's level of influence on students. These two aforementioned factors are instrumental for building the teacher's pedagogical beliefs, which can be conceived of as goals, purposes and/or reasons for the use of technology in education (Prestridge \& Prestridge, 2017). The educational context of technology goals consists of technological competencies and ICT as learning tools (Tondeur, Van Braak, \& Valcke, 2007;Downes et al., 2001). Moreover, Downes et al. (2001) maintain that the other goal of ICT is for the transition in content and pedagogy, which also describes the current practice of technology integration lessons.

A plethora of findings reveal some barriers that hinders teachers' ICT integration, and they include environmental factors (Stockdill \& Morehouse, 1992; Sherry \& Gibson, 2002; Balanskat, Blamire, and Kafal, 2007), organizational/institutional characteristics, a systemic level of barrier for ICT integration and teaching, and learning process factors. Razak, Jalil, Krauss, and Ahmad (2018) explain the systematic conditions (or culture) that facilitate successful ICT integration in school; specifically, the three contributing conditions include optimal ICT tools types, the optimal rules and regulations that shape ICT culture, and the optimal division of labour within the school community. Meanwhile, social distancing and online learning at home have been the new norm since movement control order. Thus, learning is a continuous process that can be done anywhere with customized learning. Teachers need to step out from the conventional classroom setting and figure out another way of instructing. In continuing teaching and learning, environment factors are part of the teachers' pedagogical beliefs to optimize the role of technology in teaching language skills meaningfully.

\section{Teachers' Technology Usage in ELT}

Researchers have defined the term 'technology' in numerous ways. ISMAN (2012) defined technology as the "practical use of knowledge in specific areas and is a way of doing a task especially using technical processes, methods, or knowledge. The usage is not restricted to machines (hardware devices) and instruments, but also involves structured relations with other humans, machines, and the environment (Doley, 2019). In addition, Gilakjani (2017) 
defined the 'integration of technology' as how teachers use technology to perform familiar activities more effectively and how this usage can bring innovation to these activities. In another view, Dockstader (2008) defines technology as tools used to improve the educational environment to support classroom teaching by creating opportunities for learners to complete the task with integrated technology. Gil-Flores, Rodríguez-Santero, and TorresGordillo (2017) used a general context of ICT use by teachers in two levels of division. The first level refers to the ineffective use of an educational resource that gives basic support for teachers mainly used for class preparation. The second level is the effective use of an educational resource in teachers' daily work with students. In relation to the research, the ICT usage of ESL teachers is viewed in the level of effectiveness that adapts both the definitions of Gilakjani (2017); Gil-Flores et.al (2017).

In the context of Malaysian education, Communicative Language Teaching encourages the use of technology for improving the teaching and learning of English in a CEFR aligned curriculum. The curriculum emphasizes communication and language use in the context of meaningful interaction wherein two or more individuals and the instructor converse with each other both in and out of the classroom; the emphasis is on communicative competence as the product of engaging in conversational interaction with explicit teaching of language forms, skills and strategies and consequently for language teachers to possess 'a sound understanding of the language systems knowledge base' (Ahmad Afip, Hamid, \& Renshaw, 2019; Andrews, 2003; Hakim et al., 2018). The primary goal of CLT is to reinforce the four language skills in various contexts through communication and learning (Freeman, 2008). In the broadest strokes, the teachers' role has shifted from being teacher-centered to learnerfocused whereby students should play the dominant role in implementing the activities to meet their individual needs (Sherwani \& Kilic, 2017). Technology can, however, be employed to interpret a range of different Second Language Acquisition (SLA) theories into Computer Assisted Language Learning (CALL) designs (MacAro, Handley, \& Walter, 2012), and it might be argued that language teachers ought to be able to critically select among these different pedagogical ideas (Bostancıoğlu \& Handley, 2018).

The use of technology among teachers to adapt to online learning during the MCO has been useful. Even teachers who were initially resistant have grown to accept the use of technology in concern with students' needs. According to Microsoft Malaysia News Center (2020), 87\% of educators are expected to use technology more often due to $61 \%$ from the insights are expected to begin the next school year in a hybrid learning environment involving blended learning which combines online and face to face learning. Among ESL teachers, the use of ICT is partly influenced by their pedagogical beliefs which affects how they choose to apply technology to fit with the lesson (Khader \& Jordan, 2012; Tondeur, Braak, \& Ertmer, 2017) that hold a strong indicator for their practices.

However, studies from Farrell and Bennis (2013), Jerome and Samuel (2017) and Rahman et al., (2018) converge on the point that teachers' beliefs alone could not characterize behaviour in the context of a classroom lesson. Interaction between students, the lesson, and the school environment also illustrate teachers' ICT usage. Despite personal and environment factors, Taopan, Drajati, and Sumardi (2020) provide challenges for and opportunities in English Language Teaching with ICT integration that focuses on integrating three elements namely prerequisite content knowledge, pedagogy, and technology into the 7 layers knowledge designed to implement and evaluate the curriculum and instruction with technology within the dynamic framework of Technological Pedagogical Content Knowledge (TPACK). Based on Taopan et al. (2020), the challenges from experienced ESL teachers are found to be lacking in 
digital literacies, internet issues, and lack of innovative ideas for teaching with technology. In addition, newly acquired knowledge and skills have been practiced primarily online on learning platforms in contrast with the integration of technology in face-to-face classroom lessons.

\section{Modelling Teachers' Behaviour}

Learning theory is inseparable from the teachers' knowledge of teaching methods. The theories are mostly derived from the field of psychology. Psychology describes how people feel (affect), think (cognition), and act (behavior) while educational theories describe how people learn (O'Neil, Fisher, \& Newbold, 2009). Among the variety of theories stemming from different schools of thought, some explain human developmental changes during the lifespan, while others fundamentally differ in their conceptions of human nature, how people adopt, and in what they regard as the basic underpinnings and mechanisms of human motivation and behaviour (Bandura, 1989). In analysing human development (i.e. teachers) from the perspective of social cognitive theory, the analysis is concerned with changes in the psychosocial functioning of adults as occurring in childhood. According to Bandura (1986), the model of causation on which social cognitive theory is founded and reviewed, is in triadic reciprocal determinism rather than one-sided determinism. That is to say, the causation involving behaviour, cognition, personal factors, and environmental influences operate as determinants interacting bidirectionally. However, the causal strength of influence differs for each one and does not occur simultaneously. The causal influence depends on the duration to exert its influence and activate reciprocal influences.

Three basic assumptions in Social Cognitive theory are as follows: (i) Individuals are goaldirected or and exhibit purposeful behavior;(ii) Individuals are self-reflective and capable of self-regulation; (iii) Triadic reciprocal determinism is the central component of the theory (Bandura, 1986, 1997). The latter is postulated for determining the influences of ESL teachers' knowledge and beliefs on the usage of ICT in teaching and learning. The major interactional links between the different subsystems of influence is explained as follows: Personal $\leftrightarrow$ Behaviour, Environment $\leftrightarrow$ Personal, and Behaviour $\leftrightarrow$ Environment. The Personal $\leftrightarrow$ Behaviour of reciprocal causation involving personal and behaviour factors reflects the interaction between thoughts, affect and action. Donohoo (2018) studies the productive pattern of behaviour and other consequences resulting from educators' shared sense of values, beliefs, and perception. The effect of extrinsic action, in turn, partly determines their thought pattern and emotional reactions.

The second reciprocal relationship occurs between personal characteristics and environmental influences. Teachers' characteristics are built upon beliefs, expectations, and emotional bents, and cognitive competencies are developed and modified by social influences that convey information and activate emotional reactions through modeling, instruction, and social persuasion (Bandura, 1986). Furthermore, people also evoke different reactions from their social environment according to their physical characteristics, namely age, size, race, gender, and physical appearance, apart from what they say and do. Case studies by Farrell and Bennis (2013), Jerome and Samuel (2017) and Rahman et al. (2018) agreed on the similar result with ESL teachers' classroom practices that were found to be divergent with their physical characteristics and beliefs. As part of their studies, the teachers' reaction or behaviour before and after the lesson were influenced by their interaction with the students, the nature of the lesson, and the tools used and provided. 
The third aspect of reciprocal causation in triadic systems represents the two-way influence between behaviour and environment. In everyday life, behaviour could alter environmental conditions and that, in turn, can be altered by the very conditions it creates. For example, a child, prompted by his mother, may clean his room. The clean room, in turn, affects his desire to create order and control over his environment. That, in turn, sustains his room organizing behaviour in general. The environment, however, is not necessarily a fixed entity that can impinge upon individuals until mobility is constrained, nevertheless, some aspects of the environment may encroach on individuals. Most environments, nonetheless, do not bear influence until being activated by the appropriate behaviour. For example, teachers do not influence students unless they attend their class (Vijayan, Chakravarthi, \& Arul Philips, 2016), simultaneously, teachers can also influence students' motivation (Pajares, 1992). The causal effect of bidirectionality between behaviour and environmental circumstances makes people both share the same role of the products and producers of their environment. In the same vein, the most prominent determinants influencing teachers' behaviour lies in the demographic factors, organizational, and personal factors(Zainal \& Matore, 2019).

Figure 1. The Reciprocal Determinism (Bandura, 1989)

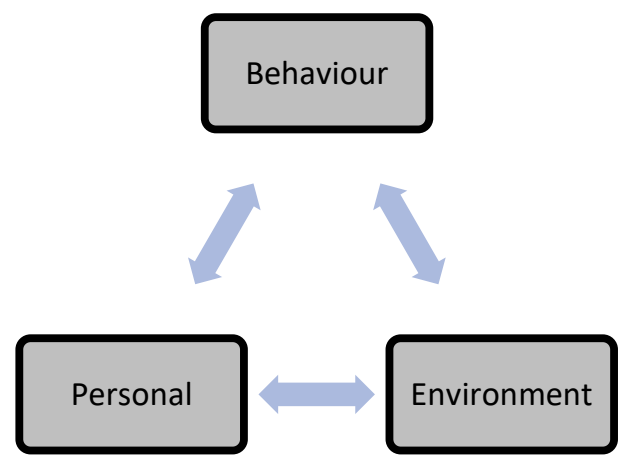

Referring to the linear effect on the behavioural change model by which the researcher needs to test multiple variable interactions to give significant relationship between the variables, Socio Cognitive theory with reciprocal determinism has identified the variables in terms of personal, cognitive, and environmental factors to determine the behaviour. Thus, it guides the research study on ICT usage in ELT to determine the influences by means of specific determinants to represent personal and environment factors. The research also signifies the significant elements from the determinants to reach the ESL primary school teachers in assessing their own teaching with technology, and the stakeholders and professional development planners to be informed of the factors that need further action.

The proposed theoretical framework to guide the research is underpinned in Social Cognitive Theory and the determinants will signify the hypotheses of the research to find the relationships and differences among groups of ESL primary school teachers in Malaysia. As knowledge is the main source for behavioural change, therefore in determining the influences from knowledge and beliefs from the triadic bidirectional relationship, technological pedagogical content knowledge (TPACK) with metacognitive approach with pedagogical beliefs consist of stages of concern and school climate are representing the subsystems of influences. 
Figure 2. Theoretical framework

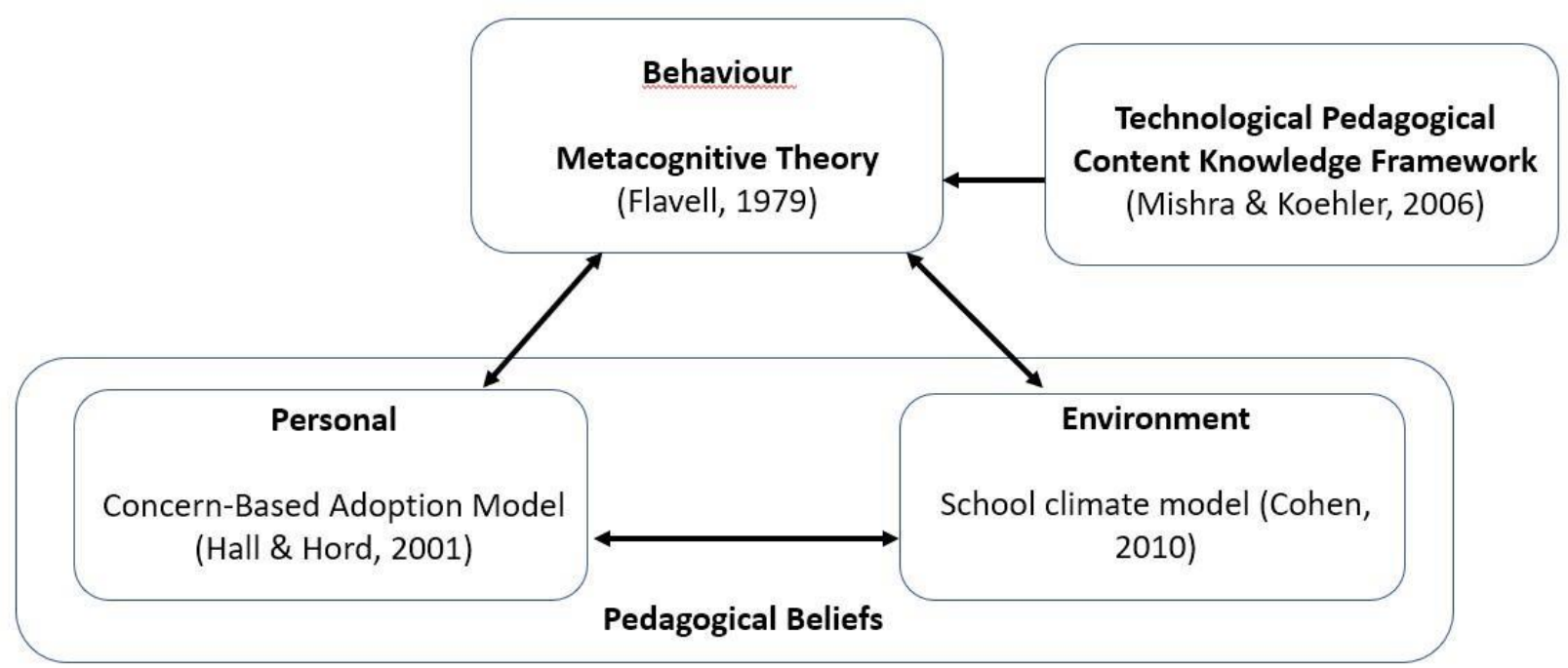

\section{Summary}

The purpose of the present study is to examine the influence of cognitive, personal, and environmental factors in a triadic reciprocal determinism on the usage of ICT among the ESL primary school teachers in Malaysia. The penetration of technology highly affects the lives of the informative community in Malaysia, which leads to more advanced experts in the field of education. This theoretical framework is strongly recommended for ESL teachers to have an overview of their own behavioural system for considering other factors such as personal and environmental influences. Besides, stakeholders and professional developers would benefit from the study by design courses based on teachers' needs and concerns, and they should also get significant support in realization of these reforms. The major contribution of this paper is that it gives Malaysian ESL teachers a data-driven guide for formulating a behavioural system.

\section{Corresponding Author}

Suhamira Nordin

University of Sultan Zainal Abidin

Email: suhamiranordin@gmail.com

\section{References}

Afip, A. L., Hamid, M. O., \& Renshaw, P. (2019). Common European framework of reference for languages (CEFR): insights into global policy borrowing in Malaysian higher education. Globalisation, Societies and Education, 17(3), 378-393. https://doi.org/10.1080/14767724.2019.1578195

Akintunde, E. A. (2017). Theories and Concepts for Human Behavior in Environmental Preservation. Journal of Environmental Science and Public Health, 01(02), 120-133. https://doi.org/10.26502/jesph.96120012

Andrews, S. (2003). Teacher Language Awareness and the Professional Knowledge Base of the L2 Teacher. Language Awareness, 12(2), 81-95. 
https://doi.org/10.1080/09658410308667068

Berry, A., Depaepe, F., \& van Driel, J. (2016). Pedagogical Content Knowledge in Teacher Education. International Handbook of Teacher Education: Volume 1. https://doi.org/10.1007/978-981-10-0366-0

Bostancıoğlu, A., \& Handley, Z. (2018). Developing and validating a questionnaire for evaluating the EFL 'Total PACKage': Technological Pedagogical Content Knowledge (TPACK) for English as a Foreign Language (EFL). Computer Assisted Language Learning, 31(5-6), 572-598. https://doi.org/10.1080/09588221.2017.1422524

Cheok, M., Wong, S., Ayub, M. A., \& Mahmud, R. (2020). ICT Integration in Malaysian Education Scenario. Retrieved from http://link.springer.com/10.1007/978-981-156157-3

Doley, D. K. (2019). Information and Communication Technology (ICT) in English Language Teaching. Proceeding, (July), 315-328. Retrieved from http://103.114.35.30/index.php/Pro/article/view/2999

Donohoo, J. (2018). Collective teacher efficacy research: Productive patterns of behaviour and other positive consequences. Journal of Educational Change, 19(3), 323-345. https://doi.org/10.1007/s10833-018-9319-2

Eickelmann, B., \& Vennemann, M. (2017). Teachers ' attitudes and beliefs regarding ICT in teaching and learning in European countries. https://doi.org/10.1177/1474904117725899

Farrell, T. S. C., \& Bennis, K. (2013). Reflecting on ESL Teacher Beliefs and Classroom Practices : A Case Study, (2003). https://doi.org/10.1177/0033688213488463

Ghavifekr, S., Razak, A., Ghani, M., Ran, N., Meixi, Y., \& Tengyue, Z. (2014). ICT Integration in Education: Incorporation for Teaching \& Learning Improvement. Malaysian Online Journal of Educational Technology, 2(2), 24-45.

Gil-Flores, J., Rodríguez-Santero, J., \& Torres-Gordillo, J. J. (2017). Factors that explain the use of ICT in secondary-education classrooms: The role of teacher characteristics and school infrastructure. Computers in Human Behavior, 68, 441-449. https://doi.org/10.1016/j.chb.2016.11.057

Gilakjani, A. P. (2017). A Review of the Literature on the Integration of Technology into the Learning and Teaching of English Language Skills. International Journal of English Linguistics, 7(5), 95. https://doi.org/10.5539/ijel.v7n5p95

Hakim, A., Abdul Aziz, A., Ab Rashid, R., Zhafirah, W., Zainudin, W., Aziz, A. H. A. A., ... Zainudin, W. Z. W. (2018). The enactment of the Malaysian common European framework of reference (CEFR): National master trainer's reflection How to cite (in APA style). INDONESIAN JOURNAL OF APPLIED LINGUISTICS, 8(2), 409-417. https://doi.org/10.17509/ijal.v8i2.13307

Hoque, K. E., Abdul Razak, A. Z., \& Zohora, M. F. (2012). ICT Utilization among School Teachers and Principals in Malaysia. International Journal of Academic Research in Progressive Education and Development, 1(4), 17-34.

Jerome, C., \& Samuel, M. S. G. (2017). Not quite what it seems: Rethinking the way we view teachers' beliefs and practices - A case study of a Malaysian ESL teacher. 3L: Language, Linguistics, Literature, 23(4), 1-14. https://doi.org/10.17576/3L-2017-2304-01

Khader, F. R., \& Jordan, A. (2012). Teachers ' Pedagogical Beliefs and Actual Classroom Practices in Social Studies Instruction, 2(1), 73-92.

Li, L. (2014). Understanding language teachers' practice with educational technology : A case from China, 46. https://doi.org/10.1016/j.system.2014.07.016 
MacAro, E., Handley, Z., \& Walter, C. (2012). A systematic review of CALL in English as a second language: Focus on primary and secondary education. Language Teaching, 45(1), 1-43. https://doi.org/10.1017/S0261444811000395

Ministry of Education Malaysia (MoE). (2018). 2018 Annual Repot: MEB 2013-2025. Ministry of Education Malaysia.

O'Neill, C., Fisher, C., \& Newbold, S. (2009). Developing Online Learning Environments in Nursing Education. AORN Journal, 90(1), 138-139. https://doi.org/10.1016/j.aorn.2009.06.015

Prestridge, S., \& Prestridge, S. (2017). Examining the shaping of teachers ' pedagogical orientation for the use of technology the use of technology. Technology, Pedagogy and Education, 26(4), 367-381. https://doi.org/10.1080/1475939X.2016.1258369

Rahman, M. M., Kaur, M., Singh, M., Lecturer, S., Pandian, A., \& Teaching, C. L. (2018). Exploring ESL Teacher Beliefs and Classroom Practices of CLT : A Case Study, 11(1), 295-310.

Razak, N. A., Jalil, H. A., Krauss, S. E., \& Ahmad, N. A. (2018). Successful implementation of information and communication technology integration in Malaysian public schools: An activity systems analysis approach. Studies in Educational Evaluation, 58(April), 17-29. https://doi.org/10.1016/j.stueduc.2018.05.003

Sequeira, A. H. (2012). Introduction to Concepts of Teaching and Learning. SSRN Electronic Journal, 1-6. https://doi.org/10.2139/ssrn.2150166

SHERWANI, S., \& KILIÇ, M. (2017). Teachers' Perspectives of the use of CLT in ELT Classrooms: A Case of Soran District of Northern Iraq. Arab World English Journal, 8(3), 191-206. https://doi.org/10.24093/awej/vol8no3.13

Tamin, N. H., \& Mohamad, M. (2020). Google Classroom for Teaching and Learning in Malaysia Primary School during Movement Control Order ( MCO ) due to Covid - 19 Pandemic : A Literature Review, 3(5), 34-37.

Taopan, L. L., Drajati, N. A., \& Sumardi. (2020). TPACK FRAMEWORK: CHALLENGES AND OPPORTUNITIES IN EFL CLASSROOMS. Journal of Chemical Information and Modeling, 53(9), 1689-1699. https://doi.org/10.1017/СВ09781107415324.004

Tondeur, J., Braak, J. Van, \& Ertmer, P. A. (2017). Understanding the relationship between teachers ' pedagogical beliefs and technology use in education : a systematic review of qualitative evidence. Educational Technology Research and Development, 65(3), 555575. https://doi.org/10.1007/s11423-016-9481-2

Tondeur, J., Van Braak, J., \& Valcke, M. (2007). Curricula and the use of ICT in education: Two worlds apart? British Journal of Educational Technology, 38(6), 962-976. https://doi.org/10.1111/j.1467-8535.2006.00680.x

Vijayan, P., Chakravarthi, S., \& Arul Philips, J. (2016). The Role of Teachers' Behaviour and Strategies in Managing a Classroom Environment. International Journal of Social Science and Humanity, 6(3), 208-215. https://doi.org/10.7763/ijssh.2016.v6.644

Webster, A., Mcneish, D., Scott, S., Maynard, L., \& Haywood, S. (2012). What influences teachers to change their practice? A rapid research review. Centre for Understanding Behaviour Change. Retrieved from http://www.bristol.ac.uk/medialibrary/sites/cubec/migrated/documents/pr7.pdf

Zainal, M. A., \& Matore, M. E. E. M. (2019). Factors Influencing Teachers' Innovative Behaviour: A Systematic Review. Creative Education, 10(12), 2869-2886. https://doi.org/10.4236/ce.2019.1012213 